\title{
Measurement of the temperature distribution at the tool-chip interface by using a cutting tool with seven pairs of built-in micro $\mathrm{Cu} / \mathrm{Ni}$ thermocouples
}

\author{
Jun Shinozuka ${ }^{1, a^{*}}$, Habibah Binti JAHARADAK ${ }^{2, b}$ \\ ${ }^{1}$ Department of Mechanical Engineering, Yokohama National University, Japan \\ ${ }^{2}$ Graduate School of Engineering, Yokohama National University, Japan \\ a*jshinozu@ynu.ac.jp, bjaharadak-habibah-yp@ynu.jp
}

Keywords: cutting, temperature, micro thermocouple, ultrasonic machining, electroless plating, electro plating, ion plating

\begin{abstract}
Knowing temperatures at the tool-chip interface is extremely important to optimize the machining condition and to improve the machining performance, furthermore to design high performance materials. In order to grasp the temperature distribution at the tool-chip interface, this study has devised an indexable insert with seven pairs of built-in micro $\mathrm{Cu} / \mathrm{Ni}$ thermocouples on the rake face near the cutting edge. This paper shows the performance of the indexable insert with built-in micro thermocouples developed. The thickness of each element of the micro thermocouple is approximately $15 \mu \mathrm{m}$. The result of unsteady heat conduction analysis employing FEM shows that the temperature difference by installing the micro thermocouples is less than $10 \mathrm{~K}$ or $1.2 \%$. The temperature measurement experiments by cutting of aluminum alloy were carried out by changing the cutting speed. The results provided the evidence that the temperature distribution at the tool-chip interface can be grasped with the indexable insert with built-in micro thermocouples developed.
\end{abstract}

\section{Introduction}

The tool wear rate is strongly affected by temperature. Some additives are contained in novel materials to control the tool wear rate and improve the cutting performance. One of the crucial functions of the additives is to promote the formation of a certain film at the tool-chip interface on the tool face, which improves the tribological property at the interface. The formation of the film at the tool-chip interface depends strongly on temperature because the thermo-chemical reaction is the principal factor for the formation of intermetallic compounds. Hence, knowing cutting temperature, especially temperatures on the tool-chip interface, is indispensable to optimize the cutting condition, improve the cutting performance and design high-performance materials.

Though many techniques for grasping the temperature on the tool surface have been proposed so far, the technique of direct measurement is few [1-5]. The author has developed a cutting tool with built-in thin film thermocouples (TFTs) for measuring the temperatures at the tool-chip interface directly $[2,3]$. For our tool with built-in TFTs, it was difficult to grasp the shape of the temperature distribution clearly, because the numbers of thermocouples were three at maximum. Moreover, TFTs fabricated on the tool face exhibited low endurance against the slide of the chip. Some improvements for direct measurement of the temperatures at the tool-chip interface are required to become practical use. In order to resolve this issue, this study has developed a new indexable insert in which seven pairs of micro $\mathrm{Cu} / \mathrm{Ni}$ thermocouples are embedded in the rake face near the cutting edge.

\section{Development of the indexable insert with seven pairs of built-in micro $\mathrm{Cu} / \mathrm{Ni}$ thermocouples}

Fig. 1 illustrates the conceptual design of the indexable insert with built-in seven pairs of micro $\mathrm{Cu} / \mathrm{Ni}$ micro thermocouples devised. Each hot junction is formed perpendicular to the rake face in each groove, as shown in Fig. 1 (a). Fig. 1 (b) shows the fabrication procedure schematically. The tool material used in this study was an alumina ceramics (KYOCERA SNGN120408 KA30). Firstly, the micro grooves corresponding to the circuit pattern of the micro thermocouples are formed by utilizing 
ultrasonic machining with a devised ultrasonic tool in which the hard thin films and the soft thin films are laminated [6]. Secondly, nickel film and copper film are deposited on the tool face by means of electroless plating and electro plating. In this process, the portion not to be deposited was covered with a masking material. Thirdly, the films deposited are removed by lapping process to leave the films in the grooves only [7]. Finally, silicon nitride $\left(\mathrm{Si}_{3} \mathrm{~N}_{4}\right)$ film as an electrical insulating film is coated on the tool face by utilizing an ion plating device. In the ion plating process, high vacuum pressure is required to vaporize silicon by electron beam. However, high vacuum pressure makes it difficult to generate and maintain plasma discharge. Thus, in this device, twelve samarium-cobalt magnets (surface magnetic flux density: $277 \mathrm{mT}$, heat-resistant temperature: $573 \mathrm{~K}$ ) were placed around the RF coil to capture electron by the magnetic field and to increase the plasma density around the coil, as shown in Fig. 2. By arranging the magnets around the RF coil, the film deposition rate achieved $36 \mathrm{~nm} / \mathrm{min}$ under a deposition pressure of $0.011 \mathrm{~Pa}$.

Fig.3 shows the indexable insert with seven pairs of built-in micro $\mathrm{Cu} / \mathrm{Ni}$ thermocouples developed. Fig.4 shows the photographs of the backscattered electron images (BEI) of the cross-section around the nose. The bright portions indicate copper. The depth of the groove for the micro thermocouple is approximately $15 \mu \mathrm{m}$ and the width of the groove is approximately $70 \mu \mathrm{m}$. Thus, the area of the hot junction is approximately $1050 \mu \mathrm{m}^{2}$. The characteristic of the thermoelectromotive force (emf) of the micro $\mathrm{Cu} / \mathrm{Ni}$ thermocouple developed was compared with the characteristic of emf of a $\mathrm{Cu} / \mathrm{Ni}$ wire thermocouple [8]. It was found that the characteristic of emf with temperature of the micro $\mathrm{Cu} / \mathrm{Ni}$ thermocouples is almost the same as that of the $\mathrm{Cu} / \mathrm{Ni}$ wire thermocouple. This fact will be shown in Fig. 8 (a) at the later section.

\section{Numerical prediction of the temperature measurement performance}

The thermal conductivity of the each element of the micro thermocouples is quite higher than that of the alumina ceramics. By installing the micro thermocouples, there might be a possibility that the
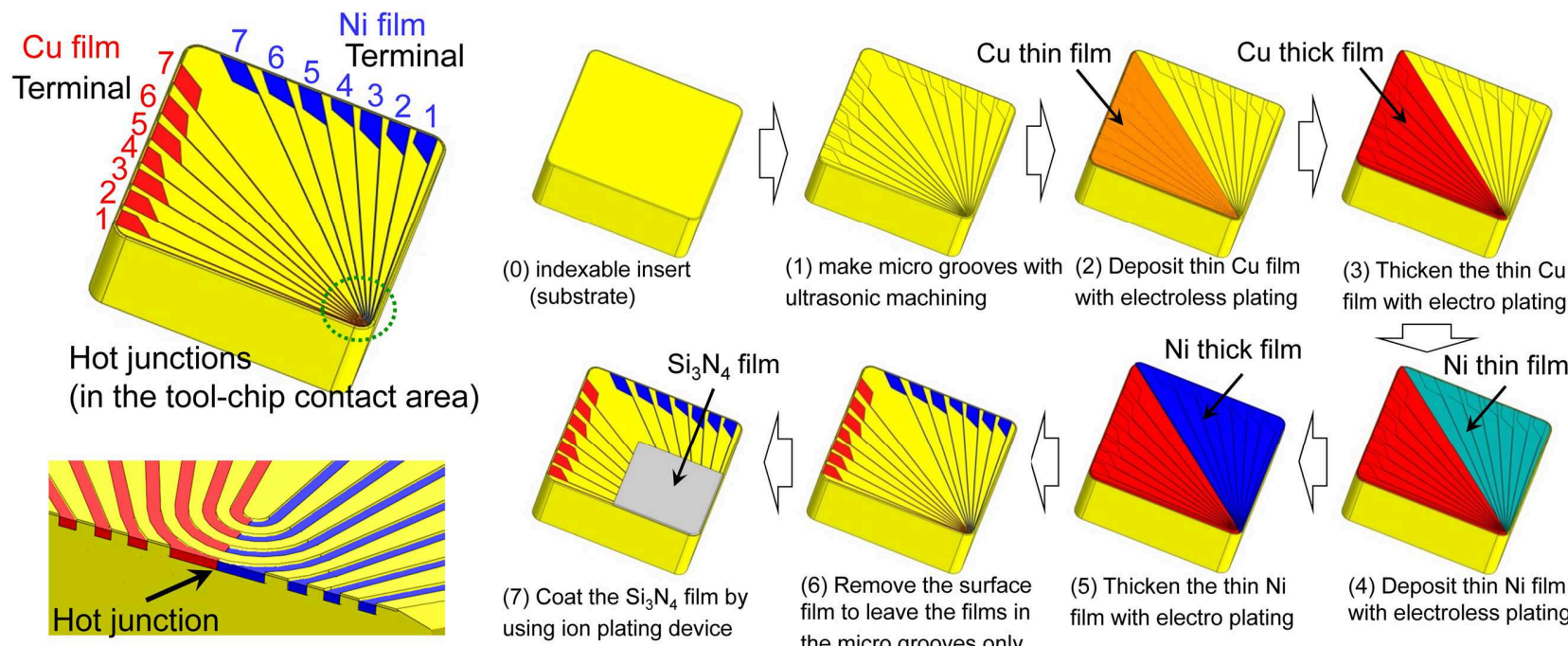
(substrate)

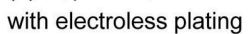

(3) Thicken the thin $\mathrm{Cu}$

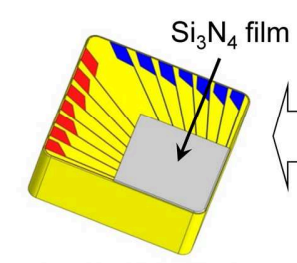

(7) Coat the $\mathrm{Si}_{3} \mathrm{~N}_{4}$ film by using ion plating device

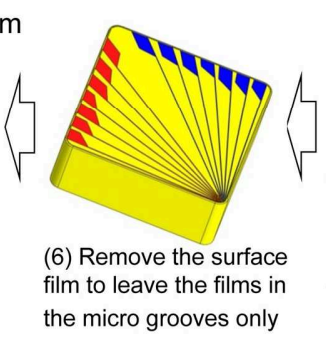

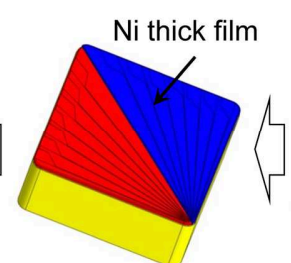

(5) Thicken the thin $\mathrm{Ni}$ film with electro plating film with electro plating

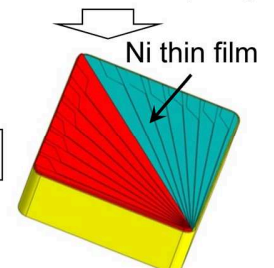

(4) Deposit thin Ni film with electroless plating

(a) cross section around hot junction

(b) fabrication procedure

Figure 1 The indexable insert with built-in seven pairs of micro $\mathrm{Cu} / \mathrm{Ni}$ micro thermocouples devised
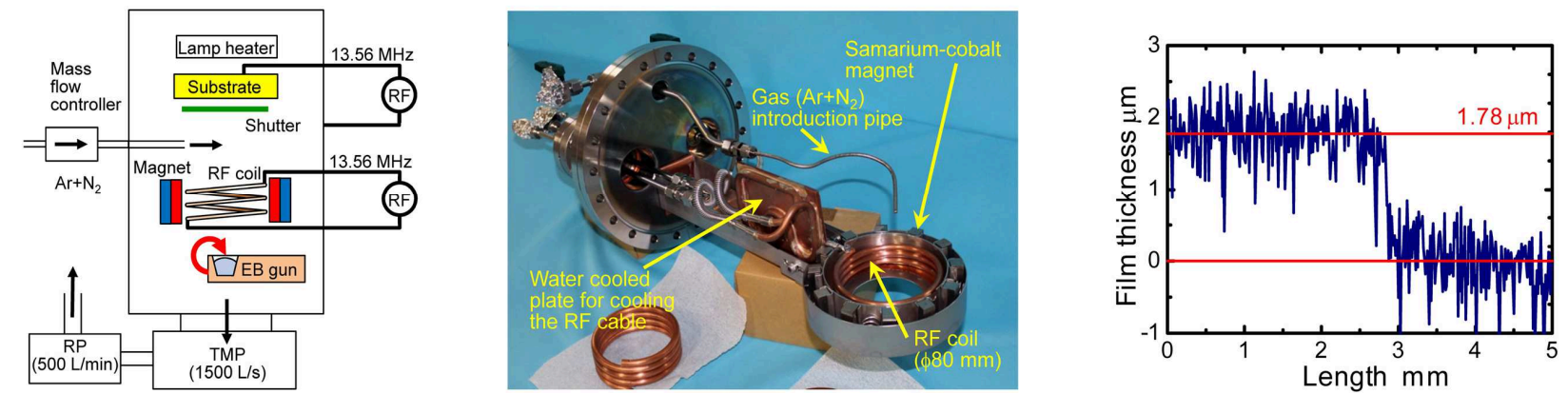

Figure 2 Illustration of the ion plating device and thickness of the $\mathrm{Si}_{3} \mathrm{~N}_{4}$ film 


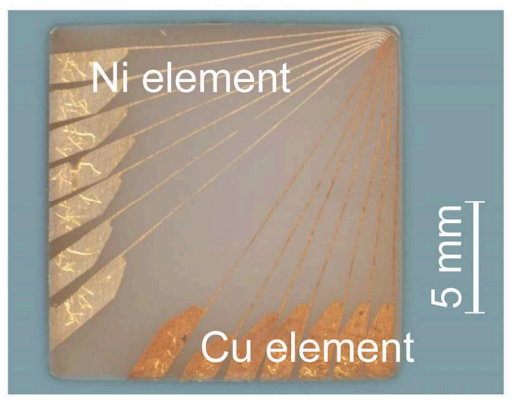

(a) before coating of $\mathrm{Si}_{3} \mathrm{~N}_{4}$ film

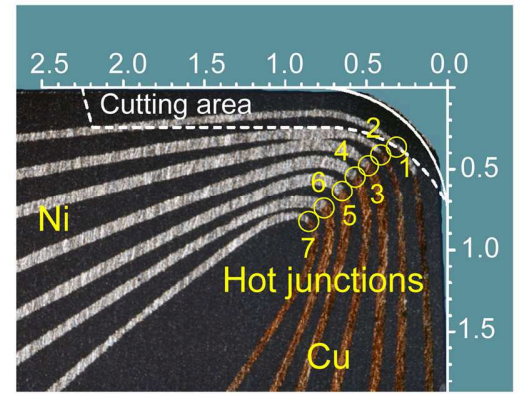

(b) around the hot junctions

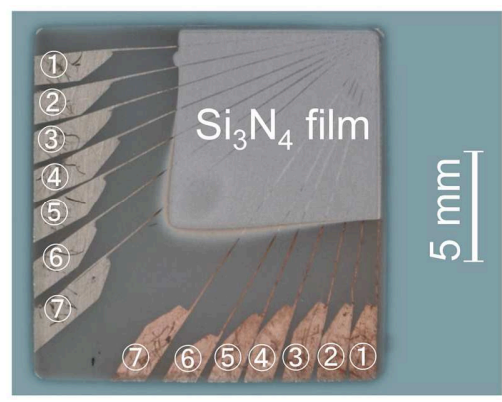

(c) after coating of $\mathrm{Si}_{3} \mathrm{~N}_{4}$ film

Figure 3 the indexable insert with seven pairs of built-in micro $\mathrm{Cu} / \mathrm{Ni}$ thermocouples developed.

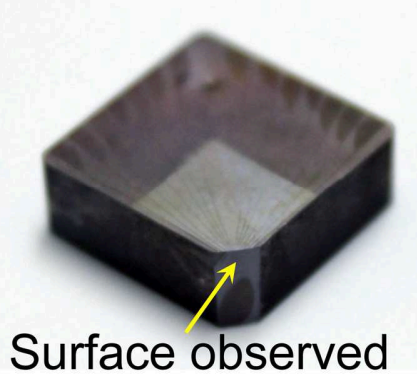

(a) surface observed

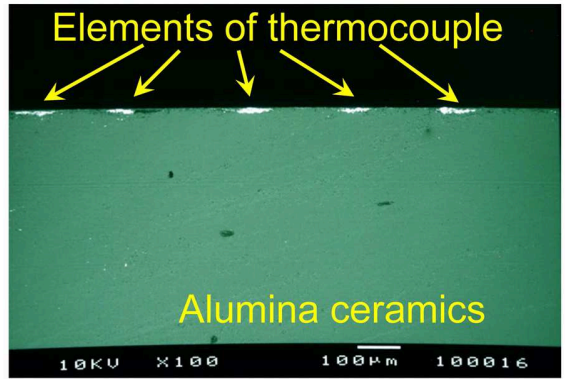

(b) photograph of BEI

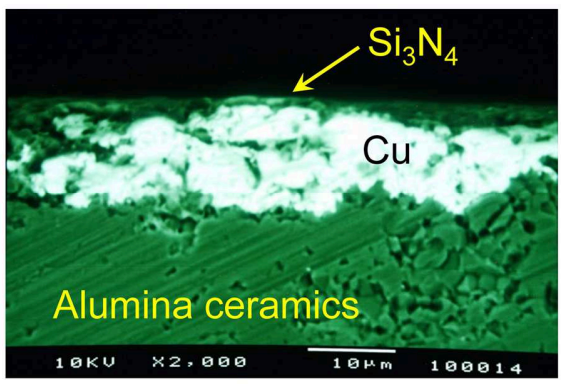

(c) photograph of BEI (enlarged view)

Figure 4 Cross section of the indexable insert around the nose of the indexable insert
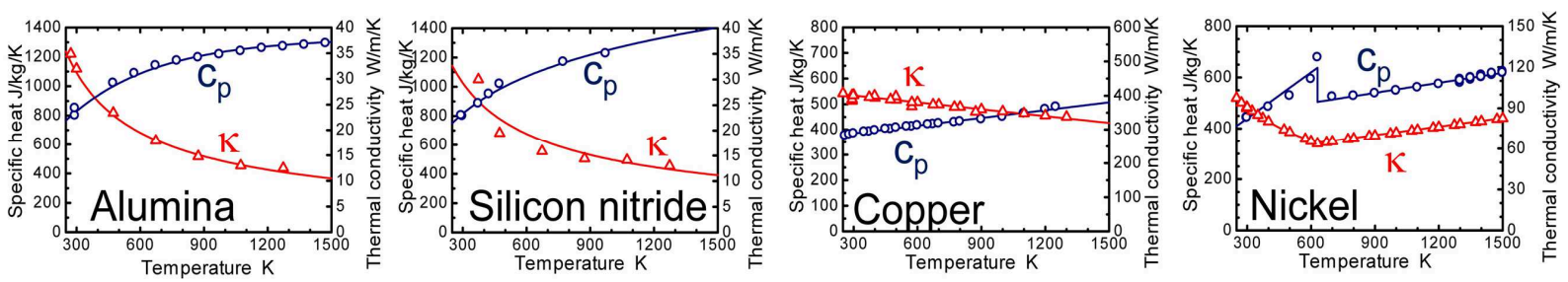

for alumina ceramics; $\quad \kappa=\exp (7.32-0.68 \ln (T)) \quad c_{p}=830+500\{1-\exp (-0.0024(T-300))\}$

for silicon nitride;

for copper;

$\kappa=\exp (6.80-0.60 \ln (\mathrm{T})) \quad c_{\mathrm{p}}=805+500\{1-\exp (-0.0030(\mathrm{~T}-300))\}$

for nickel;

$$
\begin{aligned}
& \kappa=421-0.0675 \mathrm{~T} \quad c_{\mathrm{p}}=354.4+0.102 \mathrm{~T} \\
& \kappa=\exp (7.260 .48 \ln (\mathrm{T})) \quad c_{\mathrm{p}}=260+0.60 \mathrm{~T} \quad(\mathrm{~T}<630)
\end{aligned}
$$

$\kappa=51.23+0.021 \mathrm{~T}$

$$
c_{p}=423+0.130 \mathrm{~T}
$$

Figure 5 Characteristics of the thermal conductivity and specific heat for each material

surface temperature for the indexable insert with micro thermocouples is greatly different from that for an indexable without micro thermocouples. In order to check the degree of the disturbance of the temperature by installing the micro thermocouples and to predict response performance of the micro thermocouple, unsteady heat conduction analysis was carried out by employing FEM. In this analysis, by referring data base [9] and tool manufacture's catalogs, the thermal conductivity $\kappa$ and specific heat $\mathrm{c}_{\mathrm{p}}$ for each material are set as a function of temperature $\mathrm{T}$, as shown in Fig. 5.

Fig. 6 (a) shows the FE model. The width of each micro thermocouple is $70 \mu \mathrm{m}$, the interval between them is $70 \mu \mathrm{m}$. The thickness of silicon nitride layer is $2 \mu \mathrm{m}$. A heat flux with an intensity of $10 \mathrm{MW} / \mathrm{m}^{2}$ is applied to the surface. The heat transfer coefficients to the air and alumina ceramics are assumed to be $50 \mathrm{~W} / \mathrm{m}^{2} \mathrm{~K}$ and $10^{5} \mathrm{~W} / \mathrm{m}^{2} \mathrm{~K}$, respectively. Fig. 6 (b) shows the results; change in the temperature with the thickness of the micro thermocouples at $0.5 \mathrm{~s}$ heating time. In Fig. $6(\mathrm{~b})$, the heat source intensity is constant. Fig. 6 (c) shows the temperature distribution at the cross section at the portion including $\mathrm{Cu}$ element ( $\mathrm{Cu}$ section), at the center of the FE model (alumina section) and at the portion including $\mathrm{Ni}$ element ( $\mathrm{Ni}$ section). Installing $\mathrm{Cu}$ and $\mathrm{Ni}$ decreases the surface temperature. The solid line, broken line and one point broken line indicate the temperatures for a thickness of $15 \mu \mathrm{m}, 20 \mu \mathrm{m}$ and $10 \mu \mathrm{m}$, respectively. It is needless to say that the thinner the thickness of the micro thermocouple, the less the degree of the temperature disturbance. However, from the viewpoint of the 


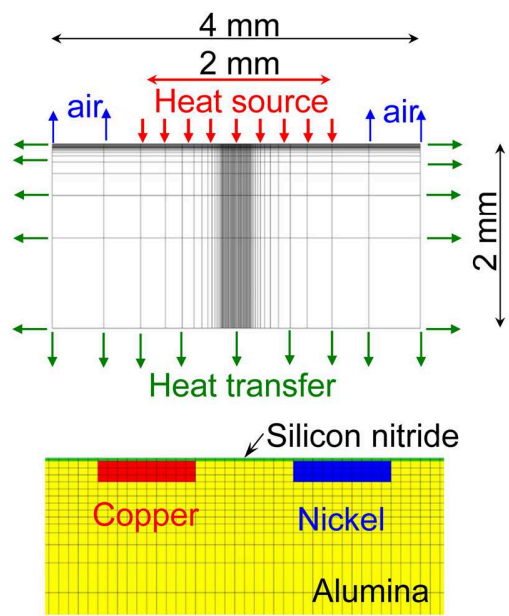

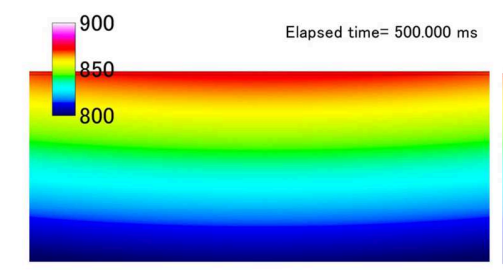

without thermocouples

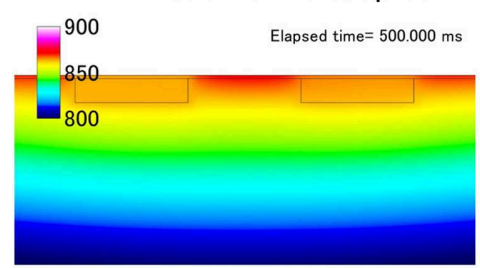

Thickness is $15 \mu \mathrm{m}$

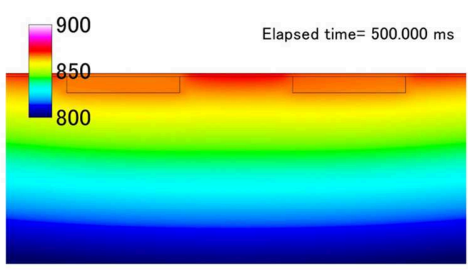

Thickness is $10 \mu \mathrm{m}$

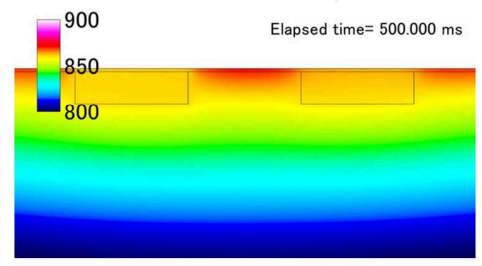

Thickness is $20 \mu \mathrm{m}$

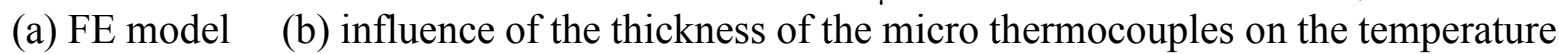

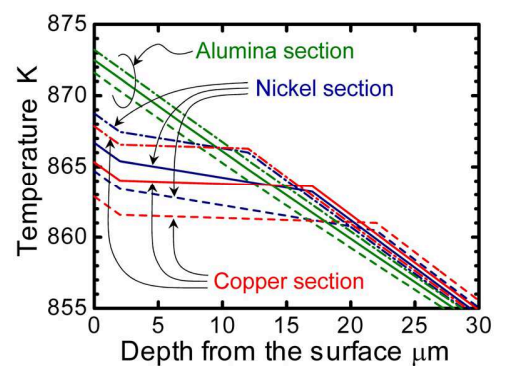

(c) temperature distribution

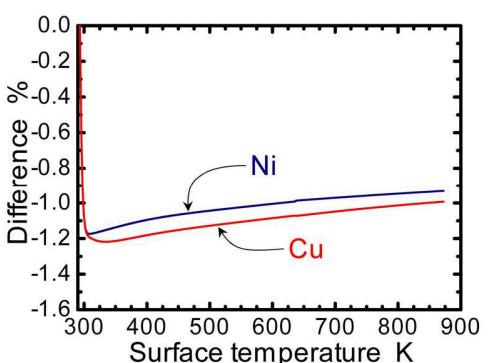

(d) temperature difference

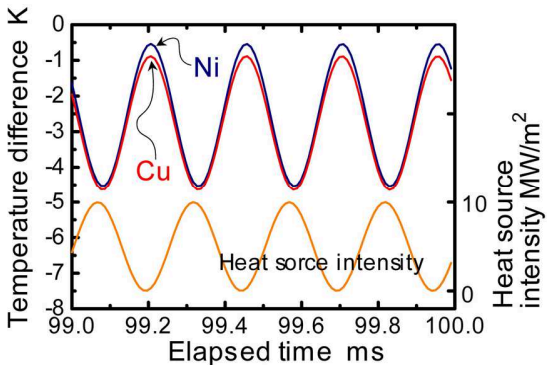

(e) response performance

Figure 6 Results of unsteady heat conduction analysis

author's experience, the endurance of the film elements for the thermocouple during cutting might decrease when the thickness of the thermocouples is thin or depth of the grooves is shallow. When the thickness is $15 \mu \mathrm{m}$, the temperature difference between the surface temperature of the alumina section and the average temperature of the part of $\mathrm{Cu}$ or $\mathrm{Ni}$ is less than $10 \mathrm{~K}$ for a surface temperature of alumina section of $873 \mathrm{~K}$. The temperature difference at various temperatures is less than $1.2 \%$, as shown in Fig. 6 (d). Fig. 6 (e) shows the result for the case that the heat source intensity is oscillated in the sine wave with a frequency of $4 \mathrm{kHz}$. When the heat source is applied to the surface, the temperature difference expands soon. The temperature difference, however, drops rapidly by following the decreasing of the heat source intensity. It is reasonable to consider that this response performance is sufficient for measuring the temperatures during turning.

\section{Temperature measurement experiment}

The cutting experiment to measure the temperature distribution at the tool-chip interface was performed by using a general purpose lathe, as shown in Fig. 7. The workpiece material was aluminum alloy A5056. The depth of cut was $2.0 \mathrm{~mm}$, and the feed rate was $0.25 \mathrm{~mm} / \mathrm{rev}$. Two kinds of cutting speeds, which was $227 \mathrm{~m} / \mathrm{min}$ and $405 \mathrm{~m} / \mathrm{min}$, were examined.

Fig. 8 (a) shows the characteristic of thermo-electromotive force of micro $\mathrm{Cu} / \mathrm{Ni}$ thermocouples with temperature. Fig. 8 (b) shows one of results obtained with micro thermocouple. From Fig. 8 (b), it can be seen that; the temperatures rise sharply when the cutting begins. The temperatures level off after the cutting time of $0.5 \mathrm{~s}$. When the cutting finishes, the temperatures drop rapidly and then decrease gradually. Since the micro thermocouples were set in the grooves, the endurance for the micro thermocouples developed was higher than that for previous TFTs that were fabricated on the rake face. 3 and 7 in this figure indicate the location of the hot junction, as shown in Fig. 3 . The distance between hot junction 3 and hot junction 7 is approximately $0.5 \mathrm{~mm}$. It can be seen that there is a high temperature gradient of approximately $150 \mathrm{~K}$ within a distance of $0.5 \mathrm{~mm}$.

Fig. 9 shows the results of the temperature distribution on the rake face including tool-chip interface. The photographs show the rake face after cutting. The circles indicate the location of the hot 

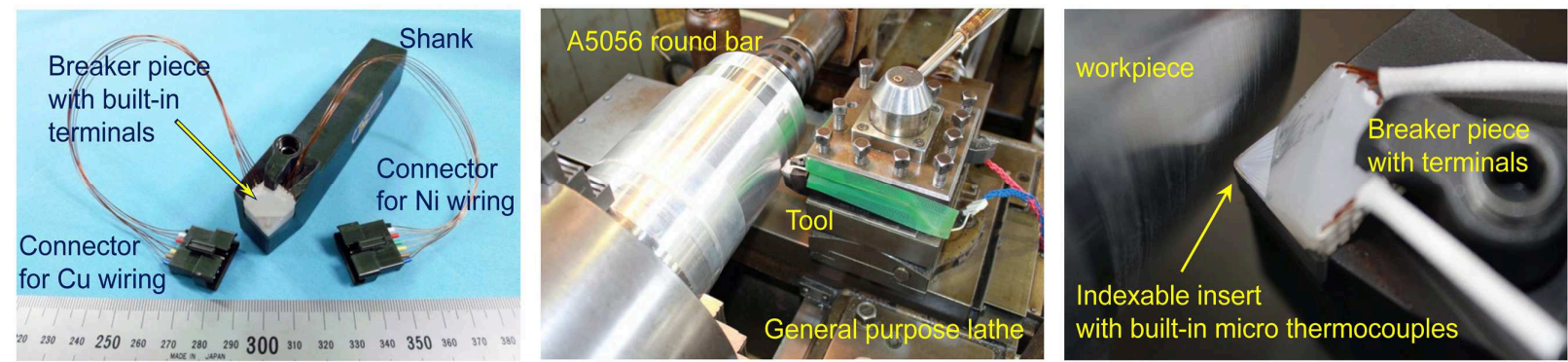

Figure 7 Appearance of cutting temperature experiment

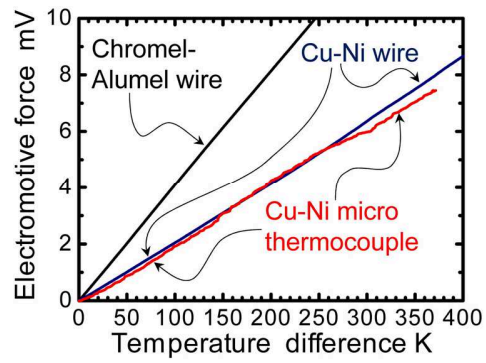

(a) property of emf

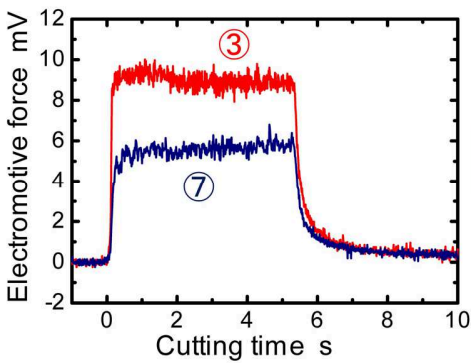

(b) one of example for the results

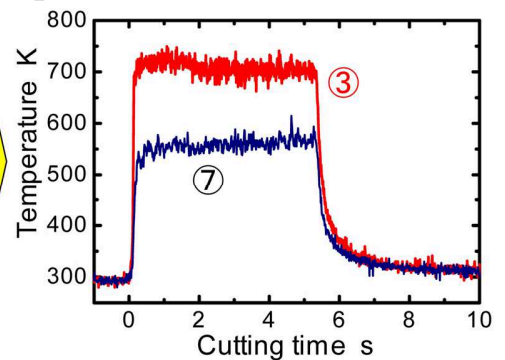

Figure 8 Example of temperatures obtained with the indexable insert with seven pairs of built-in micro $\mathrm{Cu} / \mathrm{Ni}$ thermocouples developed

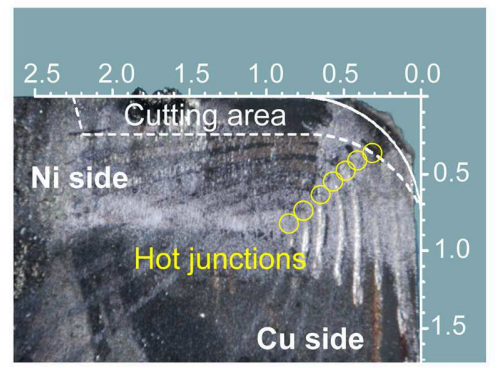

(a) cutting speed is $227 \mathrm{~m} / \mathrm{min}$

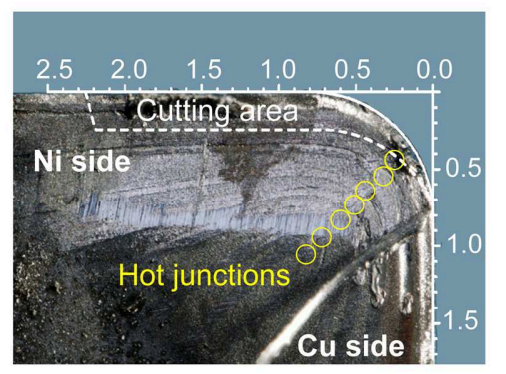

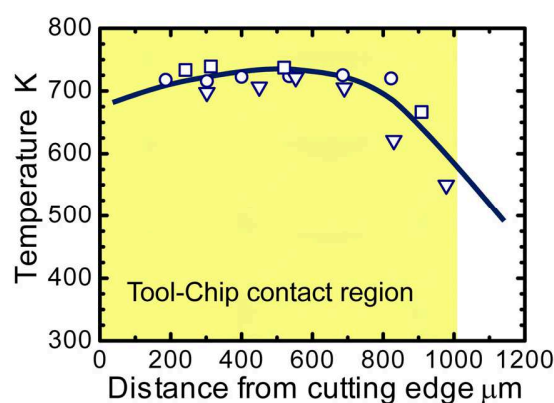

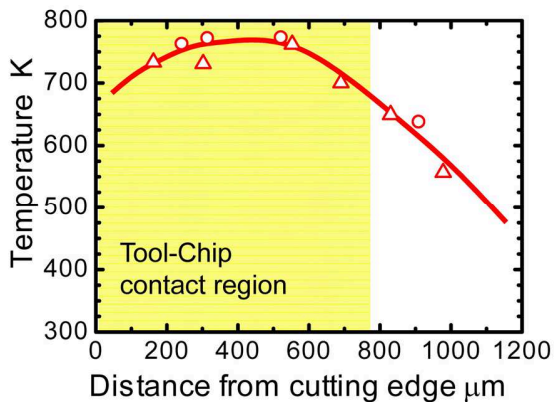

(b) cutting speed is $405 \mathrm{~m} / \mathrm{min}$

Figure 9 Influence of the temperature distribution at the tool-chip interface with cutting speed

junction. As seen from the photographs, most of hot junctions are located in the tool-chip contact region. The temperatures at a cutting time of $2 \mathrm{~s}$ are plotted in the figures. The horizontal axis in the figures indicates the distance from the cutting edge along the line where the hot junctions are located. The experiments were conducted with a plurality of the indexable inserts developed. These results are indicated with different marks $(O, \nabla, \Delta, \square)$. In the same cutting speed, the differences in the temperatures obtained are small. Therefore, it can be seen that the influence of the individual difference of the developed indexable insert on the temperature measured is small. No clear sign that the back surface of the chip had melted was observed. The melting point of the aluminum alloy A5056 is approximately $840-900 \mathrm{~K}$, and the temperatures obtained are below this temperature. Hence, the temperature distributions obtained with the micro $\mathrm{Cu} / \mathrm{Ni}$ thermocouples are valid.

As seen from the figure, increasing the cutting speed from $227 \mathrm{~m} / \mathrm{min}$ to $405 \mathrm{~m} / \mathrm{min}$ decreases the tool-chip contact length, and elevates the maximum temperature from $720-740 \mathrm{~K}$ to $770-780 \mathrm{~K}$. When the cutting speed is $227 \mathrm{~m} / \mathrm{min}$, the location that marked the maximum temperature is in 
approximately $600 \mu \mathrm{m}$ away from the cutting edge, while it is in approximately $400 \mu \mathrm{m}$ for a cutting speed of $405 \mathrm{~m} / \mathrm{min}$. Increasing the cutting speed raises the temperature gradient in the region between the cutting edge and a location that marked the maximum temperature. The difference in the temperature gradient by the difference in the cutting speed, however, disappears in the region away from the location that marked the maximum temperature.

The indexable insert with seven pairs of built-in micro $\mathrm{Cu} / \mathrm{Ni}$ thermocouples is able to obtain the temperatures at different seven points simultaneously, providing more clear shape of the temperature distribution at the tool-chip interface than the previous tool with built-in TFTs $[2,3]$

\section{Summary}

In order to grasp the temperature distribution at the tool-chip interface, the indexable insert with seven pairs of built-in micro $\mathrm{Cu} / \mathrm{Ni}$ thermocouples was developed. The thermocouples are set in the micro grooves. The temperatures obtained are valid. The results of temperature measurement experiment show clearly the difference of the temperature distribution according to the difference of the cutting speed. Therefore, the indexable insert developed can be utilized for optimizing the cutting condition, improving the cutting performance and designing materials with high-machinability.

\section{Acknowledgements}

This research was partially supported by the Ministry of Education, Science, Sports and Culture, Grant-in-Aid for Scientific Research (B) 22360059 (Japan). The author would like to acknowledge here the generosity of the organization.

\section{References}

[1] Frittz Klocke, Michael Rehse, Intelligent Tools through Integrated Micro Systems, Production Engineering, Vol. IV/2 (1997), pp. 65-58.

[2] Jun Shinozuka, Ali Basti and Toshiyuki Obikawa, Development of Cutting Tool with Built-in Thin Film Thermocouples for Measuring High Temperature Fields in Metal Cutting Processes, Transaction of the ASME, Journal of Manufacturing Science and Engineering, Vol.130, June (2008) pp.034501-1-034501-6.

[3] Ali Basti, Toshiyuki Obikawa and Jun Shinozuka, Tools with Built-in Thin Film Thermocouple Sensors for Monitoring Cutting Temperature, International Journal of Machine Tools and Manufacture, Vol.47 (2007) pp.793-798.

[4] W. Tillmann, E. Vogli, J. Herper, Dirk Biermann, Klaus Pantke, Development of temperature sensor thin films to monitor turning processes, Journal of Materials Processing Technology, Vol. 210 (2010) pp.819-823.

[5] Dirk Werschmoeller, Kornel Ehmann, Xiaochun Li, Tool Embedded Thin Film Microsensors for Monitoring Thermal Phenomena at Tool-Workpiece Interface During Machining, Transactions of the ASME, Journal of Manufacturing Science and Engineering, Vol. 133 (2011) pp. 021007-1-021007-8.

[6] Jun Shinozuka, Fabrication of multiple micro-grooves by ultrasonic machining with a tool that laminated thin hard-material and thin soft-material, Advanced Materials Research, 76-78 (2009) pp.577-582.

[7] Yuji Tomoda, Junichi Harashita and Jun Shinozuka, Fabrication of a tool insert in which micro thermocouples are embedded for monitoring cutting temperature, Proceedings of the 6th International Conference on Leading Edge Manufacturing in 21st Century, (2011), 3336 (CD).

[8] Junichi Harashita, Yuji Tomoda and Jun Shinozuka, Development of a cutting tool with micro built-in thermocouples - Characteristic of the micro $\mathrm{Cu} / \mathrm{Ni}$ thermocouples fabricated by electroless plating and electro plating -, Key Engineering Materials, Vols. 523-524 (2012) pp. 815-820.

[9] Network Database System for Thermophysical Property Data on http://tpds.db.aist.go.jp/ 